\title{
Histopathology of the Human Inner Ear in Alström's Syndrome
}

\author{
Joseph B. Nadol Jra, b Jan D. Marshall ${ }^{c}$ Roderick T. Bronson ${ }^{b, c}$ \\ ${ }^{a}$ Otopathology Laboratory, Department of Otolaryngology, Massachusetts Eye and Ear Infirmary and \\ ${ }^{\mathrm{b}}$ Harvard Medical School, Boston, Mass., and ${ }^{\mathrm{C} T}$ The Jackson Laboratory, Bar Harbor, Maine, USA
}

\section{Key Words}

Alström's syndrome · ALMS1 · Human · Histopathology ·

Inner ear

\begin{abstract}
Alström's syndrome is an autosomal recessive syndromic genetic disorder caused by mutations in the ALMS1 gene. Sensorineural hearing loss occurs in greater than $85 \%$ of patients. Histopathology of the inner ear abnormalities in the human has not previously been fully described. Histopathology of the inner ear in Alström's syndrome is presented in 2 genetically confirmed cases. The predominant histopathologic correlates of the sensorineural loss were degeneration of the organ of Corti, both inner and outer hair cells, degeneration of spiral ganglion cells, and atrophy of the stria vascularis and spiral ligament.
\end{abstract}

(c) 2015 S. Karger AG, Basel

\section{Introduction}

Alström's syndrome, first described in 1959 [Alström et al., 1959], is a rare autosomal recessive genetic disorder caused by mutations in the ALMS1 gene [Collin et al., 2002; Hearn et al., 2002]. The clinical phenotype includes cone dystrophy leading to photophobia, nystagmus, usually beginning in infancy. The retinal dystrophy progresses during childhood to include rod involvement and deteriorating visual acuity. Complete loss of vision occurs by the second decade. Greater than $85 \%$ of patients pres- ent with bilateral sensorineural hearing loss, usually beginning in the first decade of life. The hearing loss is often compounded by chronic otitis media and glue ear [Alström et al., 1959; Marshall et al., 2005, 2007a, b; Welsh, 2007; Marshall et al., 2011]. Other clinical features include truncal obesity, type 2 diabetes mellitus in $95 \%$ of children over the age of 15 years, hypertriglyceridemia, hypercholesterolemia, dilated or restrictive cardiomyopathy, hypogonadism, glomerulosclerosis leading to progressive renal failure, steatosis, steatohepatitis, or cirrhosis of the liver [Marshall et al., 2011]. Although sensorineural hearing loss is common in Alström's syndrome, the histopathology of the inner ear in the human has not been fully described. A brief description of the otopathology of cases 1 and 2 of this report can be found in Merchant and Nadol [2010a].

In a mouse model for Alström's syndrome [Collin et al., 2005], the cellular localization of ALMS1 to the basal bodies of hair cells suggests a role in ciliary function. In addition, planar polarity abnormalities of hair cell sterociliary bundles were noted. Abnormalities were detected in the ciliary bundles and dysfunction of the stria vascularis was seen in the homozygous mouse model (Alms1-/-). Progressive sensorineural hearing loss was demonstrated by auditory brainstem response thresholds and distortion product otoacoustic emission levels. Further, although initial ciliogenesis appeared normal in the ALMS1-/- mouse, abnormal positioning of the kinocilium resulted in an accelerated loss of outer hair cells from the organ of Corti and degeneration of the stria vascularis.

\section{KARGER 125}

(c) 2015 S. Karger AG, Base

$1420-3030 / 15 / 0204-0267 \$ 39.50 / 0$

E-Mail karger@karger.com

www.karger.com/aud
Joseph B. Nadol, Jr., MD

Department of Otolaryngology, Massachusetts Eye and Ear Infirmary

243 Charles Street

Boston, MA 02115 (USA)

E-Mail joseph_nadol@meei.harvard.edu 


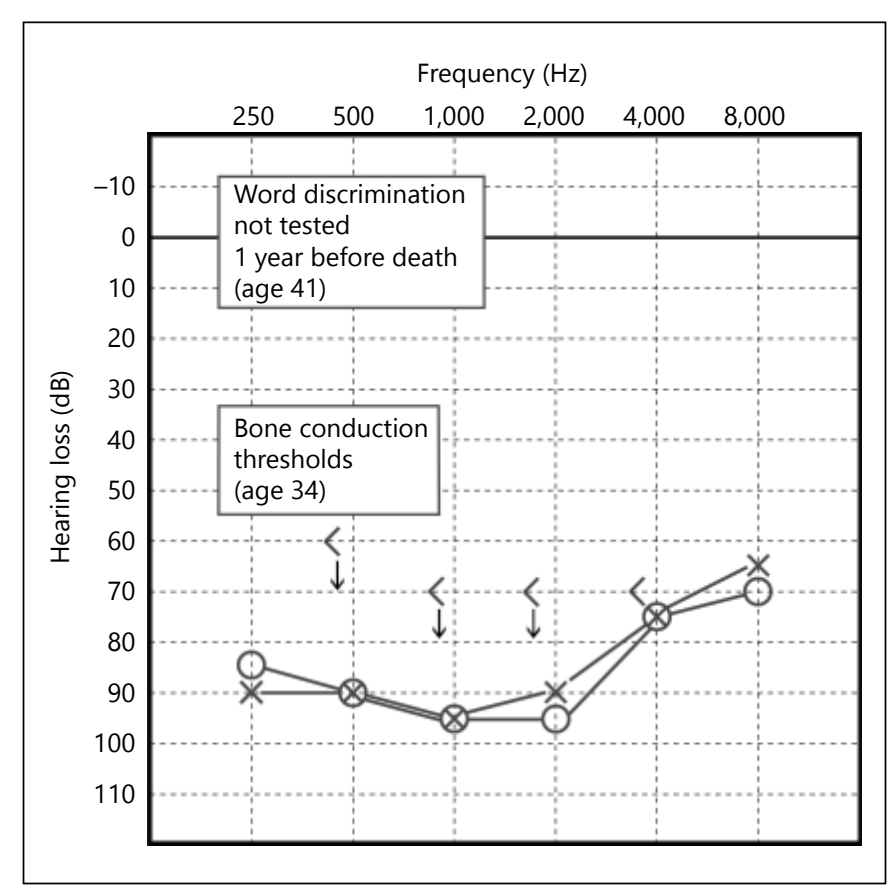

Fig. 1. Case 1. Audiogram done at age 41 years, 1 year before death. The bone conduction thresholds were last measured at age 34 . Word discrimination was not tested. The audiogram showed a severe bilateral sensorineural hearing loss most pronounced in the mid-frequencies.

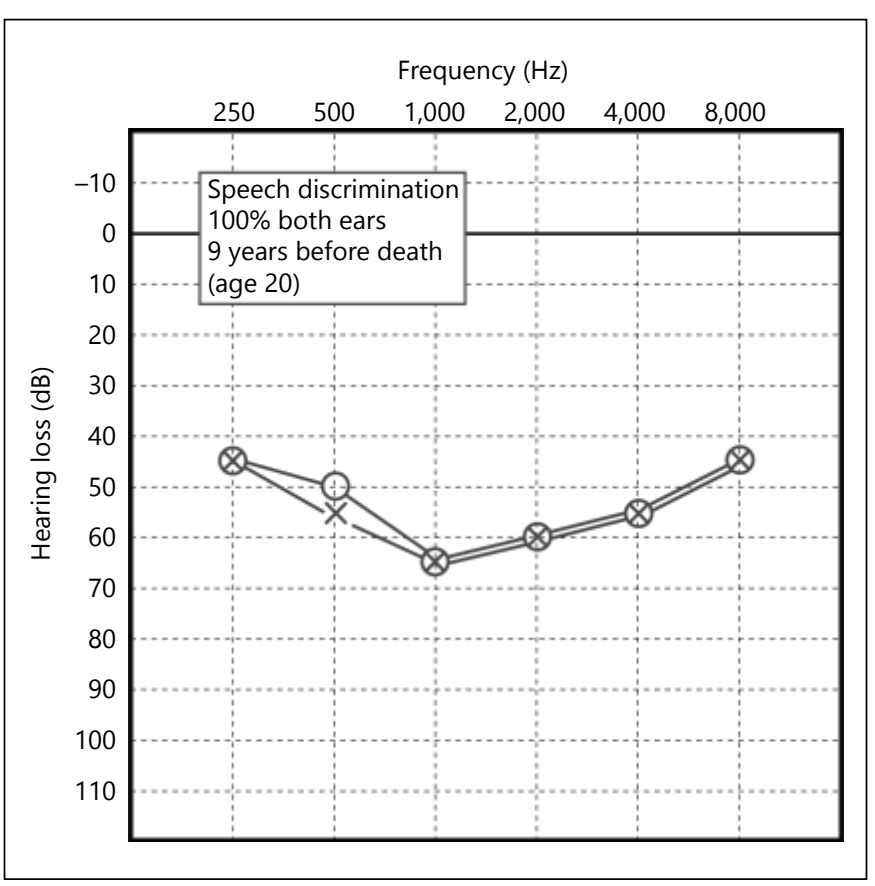

Fig. 2. Case 2. Audiogram done at age 20 years, 9 years before death. As in case 1 (fig. 1), there was a sensorineural hearing loss in both ears, most severe in the mid-frequencies.
Herein, we report the histopathology of the inner ear in 2 well-documented human cases of Alström's syndrome.

\section{Materials and Methods}

\section{Case Histories}

Case 1

This 42-year-old woman with genetically confirmed Alström's syndrome developed a hearing loss in the first decade of life. She subsequently wore hearing aids throughout life. There was a slowly progressive sensorineural loss identified between the ages of 34 and 41 . Word discrimination scores of $84 \%$ were recorded in both ears at age 38 ears. An audiogram done at age 41, one year before death (fig. 1), demonstrated a bilateral, symmetric, sensorineural hearing loss of approximately $90 \mathrm{~dB}$, PTA.

The diagnosis of Alström's syndrome was made soon after birth based on her clinical presentation and confirmed thereafter by genetic testing. She carried two heterozygous truncating mutations: c.2822T>A;p.Leu941* in exon 8 and c.11005C>T;p.Gln3669* in exon 16. As an infant she demonstrated photophobia and pendular nystagmus, progressive visual loss, and total blindness with bilateral cataracts before the age of 30 years. At 9 months of age she experienced sudden dilated cardiomyopathy and congestive heart failure, which resolved in the first year of life. At age 14, congestive heart failure recurred requiring multiple cardioversions for paroxysmal atrial fibrillation and mild dilation. She was hypertensive. She had multiple episodes of pneumonia and pulmonary hypertension. She developed hyperinsulinemia and acanthosis nigricans as a child, and type 2 diabetes mellitus in her teenage years. She was obese and short statured as an adult with a body mass index of 32.9 (greater than 95th percentile). Endocrine disturbances included hypothyroidism, hyperandrogenism, and hirsutism. She had massive hepatomegaly. She had chronic renal failure since the age of 16 and succumbed at age 42 to pulmonary failure and end-stage renal failure. The renal pathology seen in Alström's syndrome has been described [Izzi et al., 2011].

Autopsy findings included bilateral bronchopneumonia, acute respiratory distress syndrome, micronodular cirrhosis of the liver with fatty changes, splenomegaly, dilated cardiomyopathy, and atrophy of the optic nerves.

The patient's sister had a similar audiometric pattern and at age 21 years demonstrated a pure-tone average of approximately $80 \mathrm{~dB}$ in both ears, and at age 35, the threshold was $90 \mathrm{~dB}$ on the left and $80 \mathrm{~dB}$ on the right. Word discrimination scores were not tested.

Case 2

This 29-year-old man developed hearing loss first detected at the age of 7 years at which time he was fitted with hearing aids. Auditory evoked brainstem responses obtained at age 12 estimated a threshold of $32 \mathrm{~dB}$ on the right and $8 \mathrm{~dB}$ on the left. An audiogram was done at age 20 (fig. 2). This demonstrated predominantly mid-frequency, bilateral symmetric sensorineural loss with a speech reception threshold of $60 \mathrm{~dB}$ and word recognition of $100 \%$.

The diagnosis of Alström's syndrome was made based on his clinical presentation at the age of 8 years, and was confirmed by genetic testing. He had two frameshift mutations in exon 17: c.11 618_11619delCT;Ser3873Tyrfs*19 and c.11651_11652insGTTA; 
Fig. 3. Mid-modiolar section through the cochlea of case 1 . The boxed areas are shown at high magnification in figures 4,5 . There is moderate degeneration of spiral ganglion cells (SPG), particularly in the basal turns (shown at higher magnification in fig. 7).

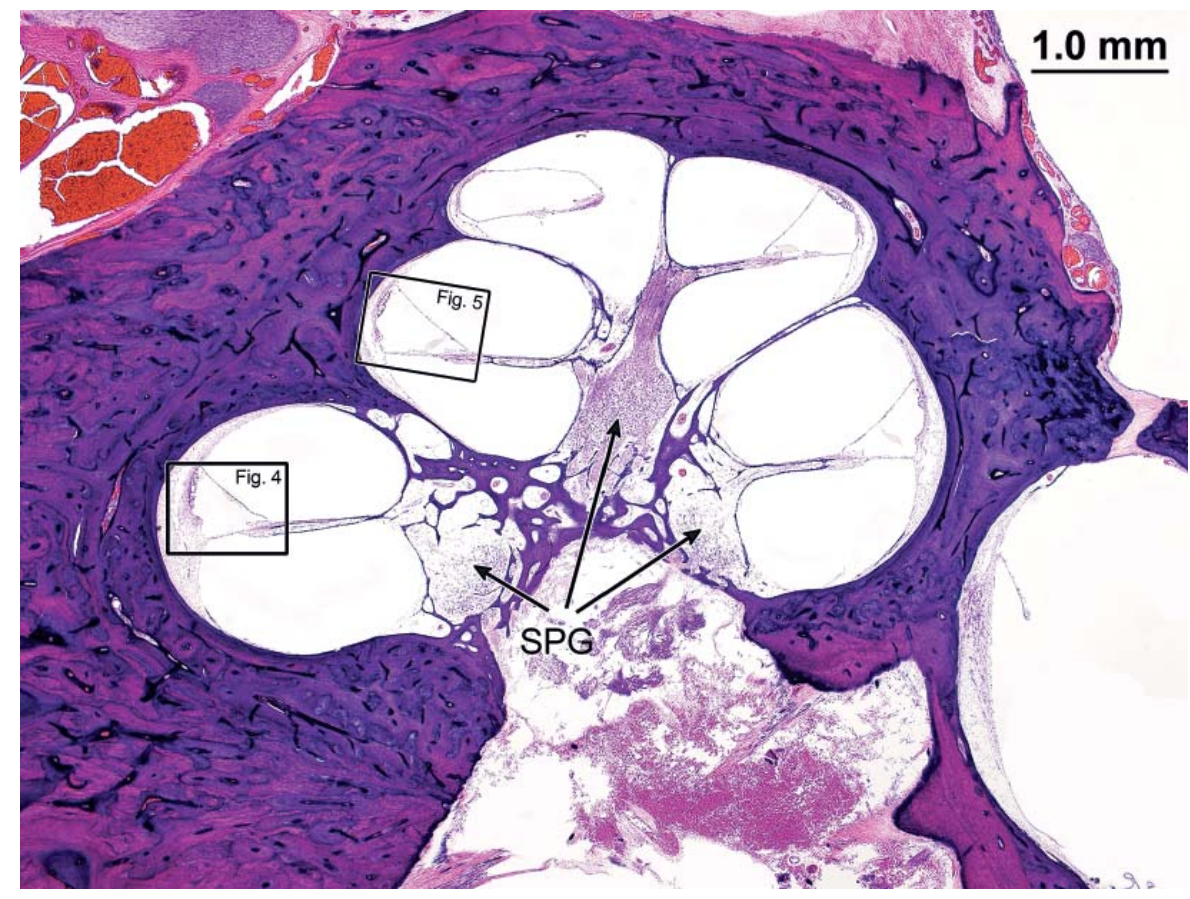

p.Asn3885Leufs*9. As an infant, his first symptoms were nystagmus and photophobia. He developed sudden onset of cardiomyopathy at 2 months of age, which resolved before the age of 2 years. His congestive heart failure and cardiac arrhythmia recurred at age 16 years. He complained of episodic dizziness and disorientation. He was obese, with a body mass index of 29.4 (greater than 90th percentile) as an adult. He had short stature, type 2 diabetes mellitus, hypothyroidism, hypogonadism, low testosterone levels, and dyslipidemia. He had reactive airway disease throughout childhood, with frequent episodes of bronchitis and pneumonia, and as an adult, chronic obstructive pulmonary disease and acute respiratory distress syndrome. He died at the age of 29 with end-stage renal failure and respiratory failure.

Autopsy findings included diffuse atrophy of endocrine glands, hepatic cirrhosis with splenomegaly and portal hypertension and hypertrophic cardiomyopathy.

Otoacoustic emission testing was not done in either patient.

\section{Histologic Preparation}

The temporal bones were removed at autopsy. The temporal bones from case 1 were fixed in $10 \%$ buffered formalin whereas in case 2, the specimens were postfixed in Bouin's fixative (picric acid) after partial decalcification in Cal-Ex II (Fisher Scientific) for 4 months (formic acid in formaldehyde). The specimens were decalcified in ethylenediaminetetraacetic acid, dehydrated in graded alcohols and embedded in celloidin.

The specimens were serially sectioned in the horizontal (axial) plane at an average thickness of $20 \mu \mathrm{m}$. Every tenth section was stained with hematoxylin and eosin and mounted on glass slides. These semiserial sections were then reconstructed by a conventional two-dimensional method, including counting of neurons of the four segments of the spiral ganglion [Guild, 1921; Merchant and Nadol, 2010b].

Histopathology of the Human Inner Ear in Alström's Syndrome

\section{Histopathology}

Case 1

The histopathology was similar on both sides and hence will be described together. The right and left temporal bones were well pneumatized, including the petrous apex. There were considerable postmortem artifact and autolysis. The estimated time was 36$48 \mathrm{~h}$ between death and fixation.

\section{Cochlea}

The cochleae consisted of 2.5 turns. The cochlear duct measured $33.3 \mathrm{~mm}$ in length on the right and $33.1 \mathrm{~mm}$ on the left. There was severe and diffuse atrophy of the organ of Corti in all three turns (fig. 3-5). In both ears, the organ of Corti was largely reduced to a flat layer of epithelial cells overlying the basilar membrane (fig. 4), or a mound of cells with no identifiable neuroepithelial elements (fig. 5). On the left side, there were small areas of residual organ of Corti in which both inner and outer hair cells were visible (fig. 6). On both the left and right side, the tectorial membrane was artifactually detached from the limbus (fig. 4). Despite considerable postmortem artifact, atrophy of the stria vascularis and spiral ligament could be identified (fig. 4, 6).

\section{Cochlear Neurons}

Rosenthal's canal measured $14.5 \mathrm{~mm}$ in length on the right and $13.1 \mathrm{~mm}$ on the left. There was degeneration of the spiral ganglion cells, particularly in the basal turn (fig. 3,7 ). The spiral ganglion cell count on the left side was 13,865 , representing $50 \%$ of normal for age, and on the right side 14,647 cells, representing $53 \%$ of normal for age.

\section{Vestibular System}

Despite considerable autolysis, an intact neuroepithelium was identified in all five vestibular end organs in both ears. Scarpa's ganglion and its dendritic processes appeared normal. The facial 
Fig. 4. Higher magnification of the organ of Corti (OC) in case 1 (see boxed area in fig. 3). The OC in the basal turn $13 \mathrm{~mm}$ from the basal end of the cochlea. There has been total atrophy of the OC, which was replaced by a layer of flat epithelial cells. The tectorial membrane (TM) was artifactually avulsed from the limbus (L). There was moderate atrophy of the stria vascularis (SV) and postmortem vacuolization.

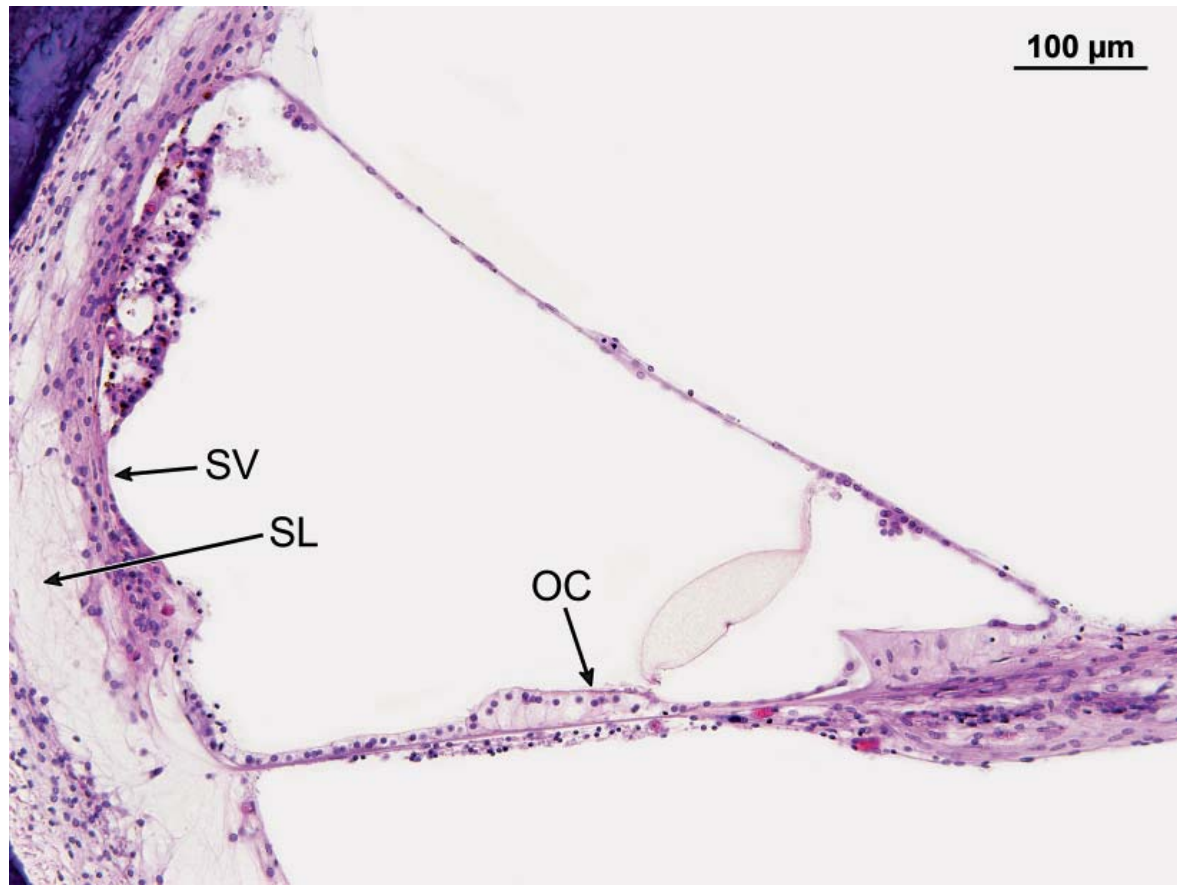

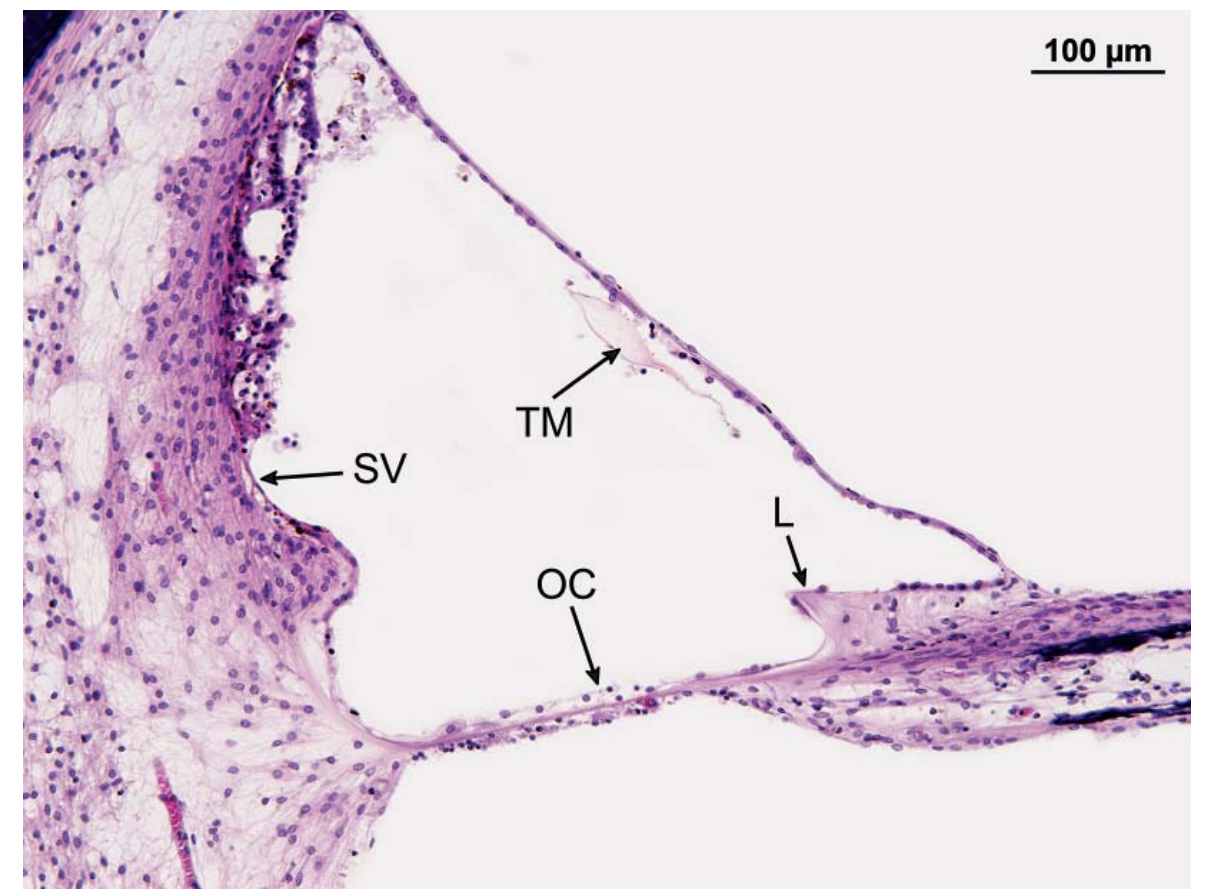

Fig. 5. Organ of Corti (OC) in the middle turn $(25 \mathrm{~mm}$ from the basal end of the cochlea) of case 1 , corresponding to the boxed area in figure 3 . The OC was replaced by a mound of epithelial cells in which there were no obvious hair cells present. There was atrophy of the stria vascularis (SV) and spiral ligament (SL). nerve, middle ear, mastoid, and tympanic membrane appeared normal.

The histopathologic correlate of hearing loss in case 1 was a diffuse degeneration of the organ of Corti with only a few hair cells, both inner and outer, remaining throughout the cochlea.
There was moderate degeneration of the spiral ganglion, particularly in the basal turn on both sides, and moderate degeneration of the stria vascularis and spiral ligament, although this was difficult to more precisely quantify because of significant postmortem artifact. 
Fig. 6. In the middle turn of the left ear (case 1), approximately $23 \mathrm{~mm}$ from the basal end of the cochlea, there were recognizable neuroepithelial cells, both inner (IHC) and outer (OHC) hair cells. There was moderate degeneration and postmortem vacuolization of the stria vascularis (SV).
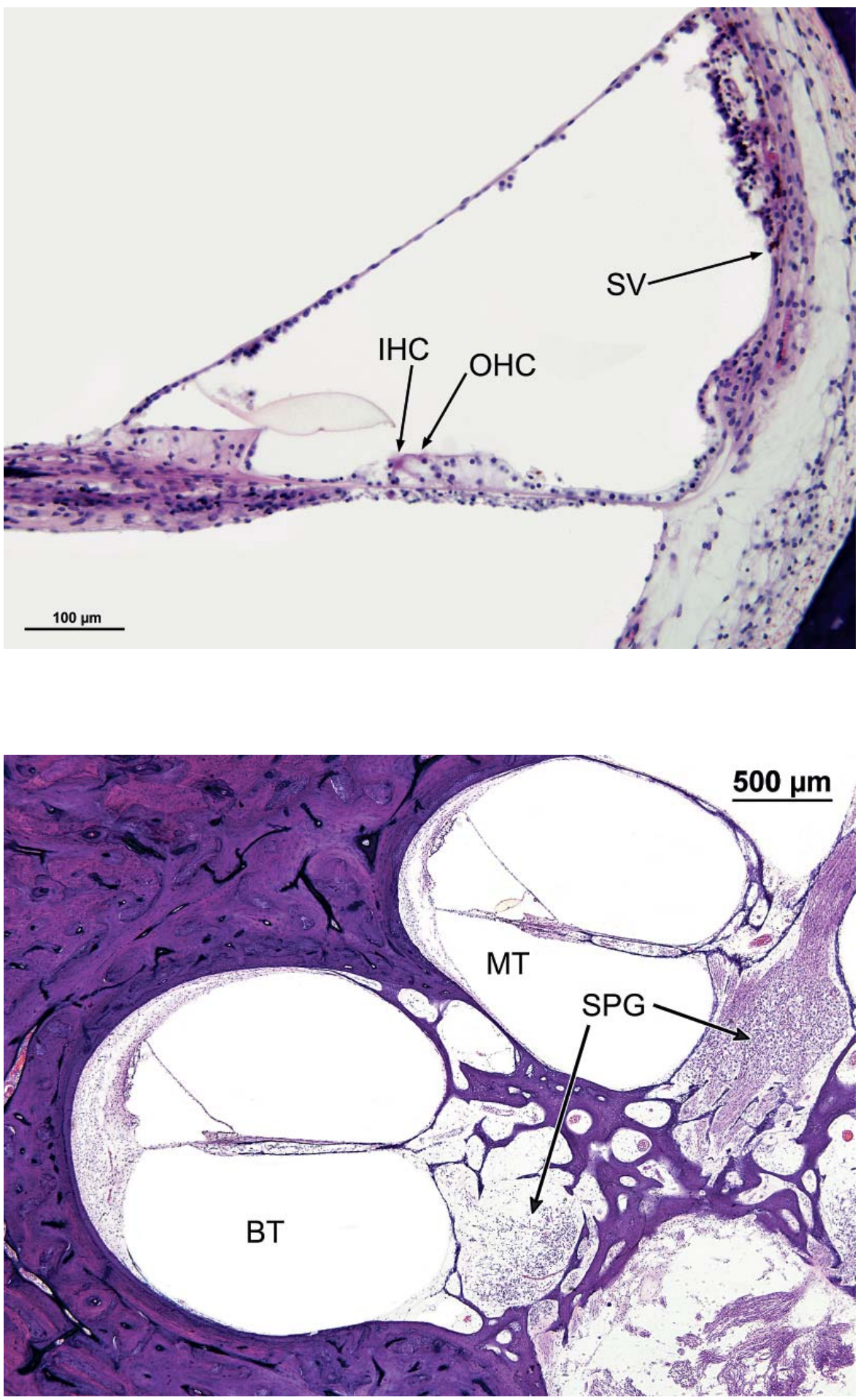

Fig. 7. Higher magnification of the spiral ganglion (SPG) also seen in figure 3 . The density of SPG was considerably reduced, particularly in the basal turn (BT), as compared to the middle turn (MT).

Case 2

The artifact was more severe in this case due to postmortem autolysis and fixation technique. The estimated time between death and fixation was $17 \mathrm{~h}$. However, the fixation was adequate to determine that similar to case 1 , the predominant histopatho- logic correlate of hearing loss was diffuse and severe atrophy of cochlear hair cells, both inner and outer. There was also atrophy of the stria vascularis and spiral ligament similar to case 1. Likewise, there was degeneration of the spiral ganglion cells, particularly in the basal turn. The spiral ganglion cell count on the right 
side was 7,110 , approximately $22 \%$ of normal for age, and on the left side 7,866 , approximately $25 \%$ of normal for age. There was no significant pathology identified in the vestibular end organs.

In summary, the audiometric pattern in both cases consisted of a sensorineural hearing loss with a mid-frequency predominance. Similarly, the histopathologic correlate of hearing loss in both cases was diffuse and severe degeneration of the organ of Corti with very few remaining hair cells present. There was also moderate degeneration and loss of spiral ganglion cells, particularly in the basal turn in both cases, and moderate atrophy of the stria vascularis and spiral ligament.

\section{Discussion}

In both cases, the predominant histopathologic correlate of the sensorineural hearing loss was degeneration of the organ of Corti with loss of inner and outer hair cells. This is consistent with the findings of Jagger et al. [2011], who described loss of outer hair cells in the Alström syndrome mouse model of Alms1-/-. However, in the animal model, significant preservation of outer hair cells in the apex was seen in the 7-month-old Alms1-/- mouse. In this mouse model, a selective loss of outer hair cells was identified, whereas in the human, both inner and outer hair cells were lost. This phenotypic difference between the mouse model and the human may be due to longer duration of hearing loss in the human cases.
In the mouse model [Jagger et al., 2011], the mice progressively lost distortion product otoacoustic emissions, also suggesting an abnormality in the outer hair cells. In a recent clinical report [Bahmad et al., 2014], otoacoustic emissions were also found to be absent in 2 siblings with Alström's syndrome while auditory brainstem responses were bilaterally normal, also suggesting a hair cell lesion. Thus, the otoacoustic emission findings both in the animal model and at least some cases of Alström's syndrome are consistent with a primary lesion at the level of the organ of Corti, specifically outer hair cells.

The mouse model and both human cases described here demonstrated a degeneration of the stria vascularis, probably not sufficient in the human to significantly affect hearing thresholds.

In addition to both inner and outer hair cell loss in the human, there was a significant loss of spiral ganglion cells, particularly in the basal turn, and more severe than can be attributed to the aging process only. This degeneration may be part of a species-specific expression of Alström's syndrome in the human or may reflect neural degeneration secondary to hair cell loss.

\section{Acknowledgments}

Supported by: NIH grant HD036878 (J.D.M.) and NIH grant U24DC011943 (J.B.N.).

\section{References}

Alström CH, Hallgren B, Nilsson LB, Asander H: Retinal degeneration combined with obesity, diabetes mellitus, and neurogenous deafness: a specific syndrome (not hitherto described) distinct from the Laurence-Moon-BardetBiedl syndrome; a clinical, endocrinological, and genetic examination based on a large pedigree. Acta Psychiatr Neurol Scand Suppl 1959;129:1-35.

Bahmad F Jr, Costa CS, Teixeira MS, Barros Filho Jd, Viana LM, Marshall J: Familial Alström syndrome: a rare cause of bilateral progressive hearing loss.' Braz J Otorhinolaryngol 2014; 80:99-104.

Collin GB, Cyr E, Bronson R, Marshall JD, Gifford EJ, Hicks W, Murray SA, Zheng QY, Smith RS, Nishina PM, Naggert JK: ALMS1 - disrupted mice recapitulate human Alström syndrome. Hum Mol Genet 2005;14:2323-2333.

Collin GB, Marshall JD, Ikeda A, So WV, RussellEggitt I, Maffei P, Beck S, Boerkoel CF, Sicolo N, Martin M, Nishina PM, Naggert JK: Mutations in ALMS1 cause obesity, type 2 diabetes, and neurosensory degeneration in Alström syndrome. Nat Genet 2002;31:74-78.
Guild SR: A graphic reconstruction method for the study of the organ or Corti. Anat Rec 1921: 22;141-157.

Hearn T, Renforth GL, Spalluto C, Hanley NA, Piper K, Brickwood S, White C, Connolly V, Taylor JF, Russell-Eggitt I, Bonneau D, Walker M, Wilson DI: Mutation of ALMS1, a large gene with a tandem repeat encoding 47 amino acids, causes Alström syndrome. Nat Genet 2002;31:79-83.

Izzi C, Maffei P, Milan G, Tardanico R, Foini P, Marshall JD, Scolari F: The case/familial occurrence of retinitis pigmentosa, deafness, and renal involvement. Kidney Int 2011;79: 691-692.

Jagger D, Collin G, Kelly J, Towers E, Nevill G, Longo-Guess C, Benson J, Halsey K, Dolan D, Marshall J, Naggert J, Forge A: Alström syndrome protein ALMS1 localizes to the basal bodies of cochlear hair cells and regulates cilium-dependent planar cell polarity. Hum Mol Genet 2011;20:466-468.

Marshall JD, Beck S, Maffei P, Naggert JK: Alström syndrome. Eur J Hum Genet 2007a;15: 1193-1202.
Marshall JD, Bronson RT, Collin GB, Nordstrom AD, Maffei P, Paisey RB, Carey C, MacDermott S, Russell-Eggit I, Shea SF, et al: New Alström syndrome phenotypes based on the evaluation of 182 cases. Arch Intern Med 2005;165: 675-683.

Marshall JD, Hinman EG, Collin GB, Beck S, Cerqueira R, Maffei P, Milan G, Zhang W, Wilson DI, Hearn T, et al: Spectrum of ALMS1 variants and evaluation of genotype-phenotype correlation in Alström syndrome. Hum $\mathrm{Mu}-$ tat 2007b;28:1114-1123.

Marshall JD, Maffei P, Collin GB, Naggert JK: Alström syndrome; genetics and clinical overview. Curr Genomics 2011;12:225-235.

Merchant SN, Nadol JB Jr (eds): Schuknecht's Pathology of the Ear, ed 3. Shelton, People's Medical Publishing House-USA, 2010a, pp 174-175, 689-690.

Merchant SN, Nadol JB Jr (eds): Schuknecht's Pathology of the Ear, ed 3. Shelton, People's Medical Publishing House-USA, 2010b, pp 34-40.

Welsh LW: Alström syndrome: progressive deafness and blindness. Ann Otol Rhinol Laryngol 2007;116:281-285. 